\title{
LETTERS
}

\section{The slippery slope argument and medical assistance in dying}

In his letter to CMAJ regarding medical assistance in dying (MAiD), Wootton asserts that "... we are likely to become more and more comfortable with it, and more and more permissive as time goes by. As slippery slopes go, this is one where the coefficient of friction also approaches zero." ${ }^{1} \mathrm{He}$ invites us to believe that there will be a steep slippery slope resulting in many errors because "few other medical acts can be accomplished with such impunity." Leaving aside the fact that the law places considerable barriers in the way of patients who wish to have MAiD, and stern penalties for physicians if they are found to have broken the law, his belief regarding slippery slopes is contradicted by plentiful evidence.

A presentation at the Euthanasia 2016 conference ${ }^{2}$ addressed the slippery slope argument. In the Netherlands, regional committees conduct annual reviews of MAiD, and the Dutch government conducts a nationwide study every five years. In addition, the government launched a survey in 2005 to gauge the public's opinion on MAiD, 20 years after it had become an established medical practice and three years after it had been formalized in statutory law.

The presentation ${ }^{2}$ reports the following:

- There has been no increase among Dutch physicians in their desire to participate in MAiD;
- There has been a decrease in the already low rate of life-ending acts without explicit patient consent;

- There has been no change in the characteristics (age, diagnosis) of those having MAiD;

- There has been no increase in the proportion of MAiD recipients who are elderly or who have "less serious" illnesses;

- Trust in physicians remains high, particularly among members of the public who are opposed to MAiD;

- Even though advance directives for MAiD are permissible in the Netherlands (this is not legal in Canada), in 2013, individuals with a dementia diagnosis represented only $2 \%$ of all MAiD deaths.

Furthermore, the issue of whether there is a slippery slope was addressed by Madam Justice Lynn Smith in her judgment in the Carter case (2012). ${ }^{3}$ Ruling in the Supreme Court of British Columbia after hearing extensive testimony from experts on both sides of the argument she concluded that " ... the evidence from other jurisdictions shows that the risks inherent in legally permitted assisted death have not materialized in the manner that may have been predicted. ... This evidence serves to allay fears of a practical slippery slope." In its own landmark judgment in the Carter case (2015), the Supreme Court of Canada accepted Madam Justice Smith's rejection of the slippery slope argument against MAiD. ${ }^{4}$
The slippery slope argument uses the fear of the unknown and is cited by opponents of MAiD. With 20 years of experience and data on MAiD being generated from many thousands of assisted deaths in numerous jurisdictions, we do not need to use conjecture or fear of the unknown.

Instead, the greater openness about death and its manner and timing that we are already seeing as a result of the change in the law is likely to lead to more complete and honest discussions between physicians and their patients about endof-life wishes.

\section{Jonathan Reggler MB BChir}

Chair, Physician Advisory Council, Dying With Dignity Canada, Comox, BC

- Cite as: CMAJ 2017 March 27;189:E471. doi: $10.1503 / \mathrm{cmaj} .732886$

\section{References}

1. Wootton J. Medical error and medical assistance in dying [letter]. CMAJ 2017;189:E31.

2. Onwuteaka-Philipsen B. Is there empirical evidence for a slippery slope? [presentation]. Amsterdam (The Netherlands): VUmc; 2016. Available: https://www.nvve.nl/files/5514/6530/4419/ Bregje-Onwuteaka-Philipsen-G107-12-05-2016.pdf (accessed 2017 Feb. 7).

3. Carter v. Canada (Attorney General). 2012 BCSC 886 [para 1241]. Ottawa: Supreme Court of Canada.

4. Carter v. Canada (Attorney General). 2015 SCC 5 [2015] 1 SCR 331 [para 120]. Ottawa: Supreme Court of Canada.

Competing interests: See affiliation. 